\title{
UM DIPLOMATA NA REVOLTA DA ARMADA: as impressões políticas e a atuação do Conde de Paço D'Arcos
}

\author{
João Júlio Gomes dos Santos Júnior*
}

\section{Resumo}

Carlos Eugênio Corrêa da Silva, o Conde de Paço D’Arcos, foi o primeiro diplomata a representar Portugal na República brasileira. Sua Missão Diplomática compreendeu o período entre 2 de junho de 1891 e 20 de novembro de 1893. Em seus relatórios sobre a situação política brasileira os argumentos de defesas da ordem social e da hierarquia militar são recorrentes, com especial destaque durante a Revolta da Armada. A proposta desse artigo é analisar fontes diplomáticas para compreender as impressões e a atuação desse diplomata durante esse conflito.

Palavras-chave: Conde de Paço D’Arcos. Diplomacia. Brasil e Portugal. Política. Revoltas Regionais.

O primeiro diplomata a representar Portugal no Brasil após a Proclamação da República brasileira foi o Conde de Paço D’Arcos. No transcorrer do período que ele ficou à frente da Legação portuguesa, entre 2 de junho de 1891 e 20 de novembro de 1893, ele acompanhou com atenção diversas disputas políticas. Dessa forma, a documentação produzida por esse diplomata é um excelente testemunho sobre o período de consolidação da República brasileira.

Entre essas disputas políticas destaca-se a Revolta da Armada de 6 de setembro de 1893, ocorrida na cidade do Rio de Janeiro. O Conde de Paço D’Arcos acompanhou de perto a primeira fase da insurgência naval contra o governo de Floriano Peixoto, e na condição de Ministro Plenipotenciário de Portugal, ele teve a oportunidade de circular entre os grupos

\footnotetext{
*Doutorando em História pela Pontifícia Universidade Católica do Rio Grande do Sul. Professor Substituto da Universidade Federal de Santa Maria. E-mail: jjjhst@gmail.com
} 
dirigentes do Estado brasileiro ${ }^{1}$. Esses dois fatores conjugados (observador/diplomata) tornaram sua documentação valiosa para estudos posteriores.

Contudo, é preciso ser cauteloso na utilização desse acervo. Antes de se tomar suas previsões, julgamentos e relatos como expressão de "sinceridade e franqueza" (COSTA, 2001, p. 217), é prudente realizar a crítica da fonte e não deixar que a grande quantidade de informações e pequenos episódios assumam preponderância sobre o exame documental. A partir desse exercício de pensar o objeto e contextualizá-lo, elencamos a sua formação militar e orientação política conservadora, como dois elementos essenciais para compreender suas defesas da ordem social e da hierarquia militar.

Portanto, a análise será dividida em três momentos. Primeiro, contextualizar-se-á a formação militar e a opção política de Carlos Eugênio pelo Partido Regenerador. Em seguida, a intervenção estrangeira na Revolta da Armada. Por último, discutir-se-á por que o governo brasileiro solicitou ao governo de Portugal a remoção desse diplomata.

\section{A contextualização do indivíduo}

As principais informações a respeito do passado de Carlos Eugênio foram obtidas junto ao prefácio biográfico escrito pelo seu filho (Henrique Corrêa da Silva), no livro que contém transcrita grande parte da documentação produzida por esse diplomata durante o período em que esteve à frente da Legação portuguesa no Brasil. Por vezes, o prefácio assume tons apologéticos do passado de Carlos Eugênio, o que não impede que se extraiam elementos pontuais que nos auxiliam na contextualização desse indivíduo. Portanto, serão analisadas, brevemente, duas dessas informações.

A primeira informação diz respeito a sua formação profissional. Carlos Eugênio Correia da Silva nasceu em 17 de dezembro de 1834 em Lisboa. Sua mãe era filha de lavradores e comerciantes da região de Paço D`Arcos e arredores. Seu pai era funcionário público da Marinha portuguesa. A primeira instrução formal recebida por Carlos Eugênio foi junto à Escola Politécnica, a qual era uma instituição de ensino voltada para a formação inicial da elite portuguesa (antigo Real Colégio dos Nobres). Logo após continuou seus

\footnotetext{
${ }^{1}$ Adotamos a classificação proposta por Edgard Carone (1983, p. 122) que define a primeira fase da Revolta da Armada entre o período que ficou marcado pela a liderança do Almirante Custódio de Melo, que vai de 06.09.1893 até 09.12.1893. Nessa data o Almirante Saldanha da Gama aderiu ao movimento dando início a segunda fase da revolta, que terminou em 13.05.1894 quando os revoltosos pediram asilo diplomático nas embarcações portuguesas. A terceira fase compreende o período entre o asilo diplomático e a morte do Almirante Saldanha em 24.06.1895. O nosso trabalho compreende apenas a primeira fase da revolta porque o Conde de Paço D’Arcos permaneceu como diplomata no Brasil até o dia 20 de novembro de 1893.
} 
estudos na Escola Naval (antiga Academia Real dos Guardas Marinhas), cuja instituição era responsável por formar o quadro de oficiais da Armada Real portuguesa. Nessa instituição, Carlos Eugênio fez a sua iniciação na Marinha portuguesa, atuando como oficial, em viagens pelo Império Colonial português.

No ano de 1876, Carlos Eugênio, que já havia entrado para política portuguesa a partir da deputação na Câmara dos Deputados ${ }^{2}$ pelo Partido Regenerador, foi nomeado Governador de Macau e Timor. Permaneceu nesse posto durante três anos, e nesse período, foi feito Visconde de Paço D’Arcos. Em 1879, Carlos Eugênio adoeceu gravemente e foi retirado da administração de Macau e Timor. Já recuperado em 1880, foi nomeado Governador do Moçambique. Atuou nesse posto até 1882, quando foi nomeado Governador da Índia, o posto mais alto da administração colonial portuguesa, onde permaneceu até 1885.

Em função de doença da esposa, Carlos Eugênio retornou para Lisboa e exonerou-se do cargo de Governador da Índia no final de 1885. Logo em seguida foi eleito Par do Reino pelo distrito de Lisboa. No início de 1888, o Visconde de Paço D’Arcos foi nomeado superintendente do Arsenal da Marinha. No dia 16 de janeiro de 1890, o Visconde de Paço D’Arcos foi nomeado Governador Civil de Lisboa e, simultaneamente com essa responsabilidade, também assumiu novamente lugar na Câmara dos Pares. Ao ser exonerado do cargo de Governador Civil de Lisboa, Carlos Eugênio foi feito Conde de Paço D’Arcos, e mais tarde, pelo decreto do governo de 4 de dezembro de 1890, o agora Conde de Paço D’Arcos, foi nomeado Ministro Plenipotenciário no Brasil ${ }^{3}$.

A análise da trajetória desse indivíduo ajuda a entender a visão de mundo que pautou suas impressões sobre a situação política brasileira entre os anos de 1891 e 1893. Carlos Eugênio era um oficial de carreira da Marinha portuguesa acostumado a assumir embarcações e postos administrativos no ultramar. No transcorrer de suas atribuições políticoadministrativas, cargos oriundos da sua condição de militar ${ }^{4}$, ele teve que enfrentar determinadas situações que colocavam tanto a ordem pública quanto a ordem social em jogo, sempre pautando suas ações pela defesa da ordem e da hierarquia.

\footnotetext{
${ }^{2}$ A Constituição de 1826 previa duas Câmaras. A Câmara dos Pares, em que seus membros tinham o tratamento de Dignos Pares do Reino, e a Câmara dos Deputados, que tinham o tratamento de Senhores Deputados da Nação portuguesa.

${ }^{3}$ Eduardo Gonçalves (1995, p. 147) adota a data de 4 de dezembro de 1890 como o dia em que Carlos Eugênio foi nomeado para Ministro Plenipotenciário no Brasil. Contudo, no prefácio biográfico escrito pelo filho de Carlos Eugênio, a data indicada é 14 de outubro (SILVA, 1974. p. XLVIII).

${ }^{4}$ De acordo com Adriana Barreto de Souza (2004, p. 164) os oficiais portugueses que circulavam pelo império ultramarino eram sempre recompensados com uma promoção. Essas promoções, por vezes, os levavam a exercer funções alheias à origem militar. Pensamos ser esse o caso de Carlos Eugênio.
} 
A segunda informação importante da trajetória de Carlos Eugênio é sua opção política pelo Partido Regenerador de Portugal. Durante a sua formação na Escola Politécnica e na Escola Naval, a sociedade portuguesa atravessava um largo período de instabilidade. As disputas entre facções políticas pelo controle do Estado dominavam o cenário político desde a Revolução Liberal de 1820. Porém, a Revolução Regeneradora de 1851 marcou a ascensão do Partido Regenerador, que consolidou a ordem social em Portugal restringindo as disputas políticas às épocas de eleições (BONIFÁCIO, 1992. p. 133).

Esse partido representava a ala mais conservadora do liberalismo português (HOMEM, 2001. p. 347). Contudo, os ganhos políticos da sedimentação da ordem foram, sem dúvidas, um grande atrativo para que Carlos Eugênio optasse por esse partido. Dessa forma, ao receber uma formação profissional-militar em que as defesas da hierarquia e ordem são dois elementos essenciais, Carlos Eugênio viu nos Regeneradores a agremiação política condizente com as ideias e valores que ele havia aprendido, sobretudo na Escola Naval.

Portanto, quando o Conde de Paço D’Arcos assumiu suas funções como Ministro Plenipotenciário, ele trouxe consigo uma visão de mundo particular que condicionou suas impressões sobre a situação política brasileira. Esse foi o caso de suas apreciações sobre a intervenção estrangeira na Revolta da Armada e mais tarde a sua atuação diplomática no conflito.

\section{Para manter a ordem: Ville Ouverte}

A Revolta da Armada iniciou em 6 de setembro de 1893. Desde o início os representantes estrangeiros acompanharam o desenrolar dos acontecimentos mais como expectadores do que como atores. Contudo, com o desenrolar do conflito, a frota estrangeira presente no Rio de Janeiro passou a ter um papel preponderante na revolta. Como os comandantes estrangeiros eram subordinados aos diplomatas, igualmente, exigiu-se muito desses no transcorrer da contenda, transformando expectadores em atores.

Alguns autores analisaram a atuação do Conde de Paço D’Arcos e emitiram suas conclusões a respeito. Para Eduardo Gonçalves (1995, p.170),

na verdade, ao longo da leitura da documentação atinente à correspondência trocada entre a Legação de Portugal no Rio de Janeiro e o Ministério dos Negócios Estrangeiros em Lisboa, relatando o evoluir da política brasileira e da posição das forças navais estrangeiras face ao conflito da Armada, perpassa uma certa simpatia pelos revoltosos, embora perante o governo 
legal se pretendesse transmitir uma imagem de eqüidistância face às partes em conflito.

Amado Cervo (2000, p. 215-216) foi mais longe ao considerar que a intervenção europeia como um todo, “embora se declarasse neutra, mal disfarçava sua simpatia pelos revoltosos, tanto é que logo provocou a hostilidade de Floriano e da opinião nacionalista da imprensa” (grifos nosso). Em nosso ponto de vista, a sua atuação foi uma reação inerente a sua condição de diplomata frente às circunstâncias da insurreição. Portanto, o objetivo deste trabalho não é julgar a atuação do Conde de Paço D’Arcos, e sim mostrar que em função das situações em que foi confrontado, ele foi obrigado a tomar determinados posicionamentos, os quais foram pautados pela defesa da ordem e da hierarquia. Assim isso se sucedeu.

Quando a insurreição teve início da Baía da Guanabara, esse diplomata logo informou o governo de Portugal sobre o ocorrido. O telegrama de 6 de setembro enviado para Lisboa informou que as legações estrangeiras receberam do governo brasileiro uma notificação de que “parte da esquadra” (SILVA, 1974, p. 255) havia se sublevado. O aviso assegurava que o governo brasileiro possuía forças para manter a ordem na cidade. Entretanto, não podia se responsabilizar caso houvesse um bombardeamento. Essa foi a estratégia de Floriano para tentar convencer representantes dos países que tinham navios no Rio de Janeiro em intervir na revolta.

Contudo, as informações recebidas do governo brasileiro contrastavam com as notícias que o Comandante inglês havia enviado para o diplomata de sua nação. De acordo com esse Comandante, toda a Marinha havia se revoltado, inclusive algumas fortalezas. Dado o desencontro de informações, no dia 7 de setembro, Carlos Eugênio solicitou que o Comandante da Mindelo permanecesse agindo de acordo com o Comandante inglês, e que o Cônsul Geral de Portugal atuasse em consonância com os Cônsules Gerais da Inglaterra e Alemanha (SILVA, 1974. p. 256).

No dia 8 de setembro, o Conde de Paço D’Arcos enviou para Lisboa um relatório mais detalhado sobre as recentes ocorrências na Capital Federal. Esse documento mostra que a intenção inicial da diplomacia era permanecer neutra frente ao conflito interno. O primeiro destaque desse relatório foi que “(...) os colegas da Inglaterra e Alemanha, sempre bem servidos pelas suas informações ocultas, tinham razão em assegurar que alguma coisa grave se tramava na sombra!” (SILVA, 1974, p. 257). O documento prosseguiu lembrando dois momentos políticos emblemáticos, que para o diplomata demonstravam "a força autoritária com que se considerava o Marechal (...)” (SILVA, 1974, p. 258). 
O primeiro foi a rejeição do habeas-corpus, ao Almirante Wandenkolk, pelo Supremo Tribunal Federal por dez votos a três. De acordo com Carlos Eugênio, até mesmo a imprensa governista clamava pela benevolência de Floriano em relação ao réu. Dessa forma, o VicePresidente planejava conceder a liberdade que o tribunal mais importante do país recusara ${ }^{5}$. O segundo foi o veto presidencial a um decreto do Congresso que visava proibir que o VicePresidente em exercício concorresse à Presidência ${ }^{6}$.

Esses dois eventos políticos deixavam transparecer, de acordo com a leitura política do Conde de Paço D’Arcos, que Floriano Peixoto não estava disposto a entregar o governo. A estratégia seria demonstrar a sua indispensabilidade ao poder, uma vez que não era alcançada a paz nos estados. Tudo fazia crer a esse diplomata que a ditadura estava próxima. Contudo, “a oposição levantou pois a cabeça começando a analizar os factos com acrimônia; mas ainda assim, nada fazia prever - aos que não fossem iniciados nos misterios da conspiração - que tão breve se desse qualquer acontecimento grave” (SILVA, 1974, p. 258).

Ainda de acordo com o relatório do dia 8 de setembro, o que chamou a atenção desse diplomata, é que no dia 4 de setembro, apenas dois dias antes de iniciar a revolta naval, ele viu o Ministro das Relações Exteriores do Brasil e o Diretor Geral andando completamente despreocupados de cuidados. Parecia que eles não estavam sabendo de nada do que se tramava. Ainda no mesmo dia 4, Carlos Eugênio encontrou Custódio de Melo em passeio público e conversou com o Almirante sobre a situação política do Brasil. Esse teria dito:

como este homem (o Marechal), tem conseguido tudo com a sua velhacaria a que dão o nome de política! Até reduz o tribunal mais superior! Note bem! Ao papel de capacho a que limpa as botas! Já não cae senão à força de bala! E o paiz não se levanta!... Isto está perdido (SILVA, 1974, p. 258-259).

O que poderia ser interpretado como desânimo, segundo o Conde de Paço D’Arcos, era "a preocupação de espírito e a bem natural comoção de quem pouco mais de trinta horas depois ia lançar-se em nova e arriscada aventura, tentar um novo e audacioso golpe de mão” (SILVA, 1974, p. 259). O relatório prosseguiu descrevendo com pormenores a visita de um enviado do governo brasileiro a todos os representantes estrangeiros na noite do dia 6 para o dia 7 de setembro.

\footnotetext{
${ }^{5}$ Com o início da revolta, o Almirante Wandenkolk permaneceu preso.

${ }^{6}$ De acordo com Hélio Leôncio Martins (1997, p. 363), “Chamou-se 'Lei da Inelegibilidade’ a que regularia o processo de eleição do presidente e do vice-presidente. Em seu art. 5, dizia: 'É inelegível para o cargo de presidente e vice-presidente da República o vice-presidente que suceda o presidente, verificada a falta deste’. O veto aposto por Floriano foi considerado, pelos revoltosos da Marinha, como em causa própria”.
} 
O emissário era o Primeiro Tenente da Marinha Henrique Sadok de Sá, ajudante de ordens do Marechal Floriano. Ele entregou um convite idêntico aos representantes de Inglaterra, Portugal, Itália, Alemanha, França e Estados Unidos. O documento expunha que o governo brasileiro tinha forças e recursos para reprimir a revolta, mas não para impedir o bombardeamento da Capital Federal. Portanto, era feito um convite aos representantes estrangeiros para apoiar o governo e impedir uma desgraça. Uma reunião para o dia seguinte era convocada, com a participação de todos os diplomatas, para resolverem o que entendessem. O Conde de Paço D’Arcos teria respondido ao Primeiro Tenente nos seguintes termos:

Respondi "que a conferencia pedida, ou à qual era convidado pelo Snr. Marechal, considerava-a eu como um acto muito grave e de muita responsabilidade, para que ousasse aceder sem ter tido tambem primeiramente uma conferencia com os colegas em que por unanimidade nos decidíssemos a aceitá-la. Que na falta dessa unanimidade, ou quando houvesse divergências, eu pela minha parte me julgaria obrigado a consultar o meu governo, facto esse, que a ter logar e acarretado forçadas demoras, bem pouco se coadunava com a urgência exigida. Que tendo o Marechal por si as fortalezas fieis e bem artilhadas, não precisava mais nada para evitar, ou fazer cessa de prompto, qualquer bombardeamento de poucos navios - que não constituíam uma potente esquadra e que não tinha onde ir buscar os recursos que o Marechal possuía! E que, finalmente, o appoio dado pelos ministros nunca poderia ser outra coisa mais do que a opposição feita pela força dos seus navios de guerra, o que se tornaria n'uma verdadeira intervenção nos negócios internos do Brazil, nas suas questões partidárias, acção que nenhum ministro praticaria sem ordem expressa do governo, por ser contraria a todas as leis do direito internacional” (SILVA, 1974, p. 262).

No dia seguinte, todos os diplomatas se reuniram e compararam as cartas que haviam recebido e decidiram recusar o convite do Marechal Floriano. Dessa forma, cada um emitiu um telegrama com as suas palavras, para não parecer que pretendiam uma imposição coletiva.

Esse relatório do dia 8 de setembro demonstra, portanto, qual era o posicionamento dos representantes estrangeiros no início da Revolta da Armada. A princípio, o objetivo era não se intrometer diretamente no conflito, embora o governo brasileiro estivesse solicitando a intervenção abertamente.

Carlos Eugênio enviou mais notícias sobre o desenrolar do levante da Marinha em 10 de setembro. De acordo com esse relatório, o comércio estaria paralisado, pois a esquadra bloqueara a chegada de navios mercantes. Essa situação fez o diplomata gerar projeções sobre o futuro da revolta, pois a falta de gêneros de primeira necessidade poderia desencadear uma revolta popular, que somada ao medo de um bombardeamento, poderia forçar o Marechal a 
renunciar o governo, ou então, a abandonar a cidade aos revoltosos e constituir um governo no interior. Porém, Carlos Eugênio considerava mais exeqüível a possibilidade dos navios deixarem a Capital Federal e se dirigirem ao Sul do Brasil para se unir à Revolução Federalista (SILVA, 1974. p. 264-267). A descrição desse relatório mostrou o despreparo da cidade para enfrentar a situação.

No dia 12 de setembro, o Almirante Custódio de Melo anunciou que no dia seguinte, às 9h da manhã, iniciariam os bombardeamentos às fortalezas que permaneceram fiéis ao governo. Nesse relatório, o Conde de Paço D’Arcos explicitou sua preocupação com a ordem social. $\mathrm{O}$ ataque às fortalezas se efetivou tal qual fora anunciado, porém algumas granadas arrebentaram dentro da cidade causando pânico à população.

Não se pintam as cenas de terror que por ali se deram! As lojas fechavam, as casas eram abandonadas pelas famílias! E pelas ruas e praças viam-se mulheres, crianças e homens enlouquecidos pelo terror, procuravam em desapoderada fuga alcançar os subúrbios da cidade, onde ao menos não ouvissem o troar da artilharia e o assobiar dos projéteis (SILVA, 1974, p. 270).

Esse bombardeamento foi explorado pelos jornais governistas como um ataque direto à cidade. A ideia era associar o nome do Almirante Custódio com o terror do bombardeio. Contudo, aos olhos de Carlos Eugênio, um experiente militar, todos os tiros que chegaram a atingir a cidade, assim como as granadas que explodiram, ou eram tiros perdidos, ou uma resposta aos ataques governista. O documento descrevia que o governo havia colocado peças de artilharia em pontos estratégicos, e que essas faziam ataques provocativos às embarcações insurgentes.

Entre os dias 14 e 15 de setembro aconteceram reuniões dos comandantes estrangeiros. Desses encontros foi elaborada uma proposta enviada para o Almirante Custódio de Melo, solicitando o aviso com algumas horas de antecedência, os horários das operações de guerra contra as fortalezas, para segurança dos navios e população estrangeiros. A resposta do Almirante foi negativa, pois considerava que não havia condições de estabelecer os horários dos combates, porque era impossível permanecer sem responder às provocações das artilharias que haviam sido colocadas no alto dos morros da cidade. O Conselho de Comandantes estrangeiros solicitou a intervenção diplomática para que as baterias de defesa do governo parassem de hostilizar os navios revoltosos, sob pena de não poder considerar o Rio de Janeiro ville ouverte (Cidade Aberta), segundo o Direito Internacional. 
Os representantes diplomáticos de Portugal, Inglaterra, França e Itália foram até o Palácio do Itamaraty solicitar oficiosamente que o governo garantisse a suspensão das hostilidades à esquadra rebelde. O Conde de Paço D’Arcos relatou à Lisboa que o Ministro inglês tomou a palavra, como decano, e disse ao Ministro das Relações Exteriores, o Dr. João Filipe Pereira, o que pensavam os representantes estrangeiros. Os argumentos da diplomacia residiam em considerar os ataques das artilharias governistas como “(...) absolutamente inútil e ineficaz (...)” e que “(...) só resultavam terror, prejuízo e perigos!”. Dessa forma, os diplomatas pediam oficiosamente, “(...), que se pezassem estas circunstâncias e que por bem da humanidade, para obviar a tantos males solicitávamos que fossem retirados aqueles inúteis canhões (...)” (SILVA, 1974, p. 274-275). Se o governo aceitasse esse pedido, os diplomatas garantiriam, através da frota estrangeira, o impedimento de qualquer bombardeio à Capital Federal pelos revoltosos.

Para Sérgio Corrêa da Costa (1945, p. 53), essa "imposição era excessiva e injustificável. Se o objetivo era dar ao Rio o caráter de cidade aberta, não o alcançavam com a simples retirada das peças”. Segundo o autor, “o que expõe uma cidade ao bombardeio não é a existência de fortificações mas a intenção de defesa e de resistência”. De acordo com essa leitura do Direito Internacional, o Rio de Janeiro jamais poderia ser considerado Cidade Aberta, uma vez que o governo jamais abdicou de se defender e resistir.

O Conde de Paço D’Arcos e os demais diplomatas estrangeiros foram, na manhã do dia 16 de setembro, ao Ministério das Relações Exteriores, receber do Ministro a resposta de Floriano Peixoto. João Felipe Pereira informou aos diplomatas que o Marechal julgava impossível retirar a artilharia de cima dos morros, mas que prometia que não se faria fogo contra os navios revoltosos, a menos que fossem praticados "atos hostis" contra a cidade (SILVA, 1974. p. 275).

A promessa do governo foi transmitida aos comandantes estrangeiros, que por sua vez, enviaram nota ao Almirante Custódio de Melo, dizendo confiar que não haveria "atos hostis” contra a cidade. Logo em seguida, os diplomatas retornaram ao Ministério por dois motivos. O primeiro motivo foi informar ao governo que os comandantes haviam enviado essa nota ao chefe revoltoso. O segundo foi ouvir a resposta do governo, ao pedido feito naquela manhã, de que as fortalezas cessassem o fogo durante algumas horas do dia, para facilitar a entrada e saída de navios estrangeiros da baía. O governo recusou essa solicitação, mas indicou que seria feito alguma sinalização às embarcações para essas operarem em segurança (SILVA, 1974. p. 276). 
O documento do dia 16 de setembro é, portanto, indicativo dos objetivos que os países estrangeiros tinham no conflito. A questão central, que permeia todo relatório, é a preocupação em relação à possibilidade de bombardeamento da cidade pela frota insurrecionada. Os danos que seriam causados por esse ato “desumano” iriam provocar a desordem e o caos. Nesse sentido, o Conde de Paço D’Arcos externou sua preocupação em relação a essa possibilidade na sua documentação. Para ele, era imperioso que a ordem fosse mantida à outrance, e que o bombardeio fosse evitado. O seu posicionamento nos primeiros dias do conflito, em que ele teve que tomar decisões em nome do seu país, foi balizado pelo pressuposto da ordem. Em nosso ponto de vista, essa orientação foi um reflexo de sua formação político-profissional.

O seu posicionamento frente à revolta só foi referendado pelas ordens recebidas do Ministério dos Negócios Estrangeiros de Portugal em 23 de setembro, que dizia que,

O Governo de Sua Majestade não reputa o Governo brasileiro responsável pelos prejuízos que nas atuais lutas civis circunstâncias de força maior possam trazer aos nossos nacionais residentes no seu território, mas considera empenhada a responsabilidade daquele Governo desde o momento que se não empreguem todos os possíveis esforços para garantir a segurança da vida e bens dos súditos portugueses (SILVA, 1974, p. LV).

No telegrama de $1^{\circ}$ de outubro, o Conde de Paço descreveu para o seu Ministro as recentes ocorrências na Capital Federal. O documento informava que há dois dias o Almirante Custódio estava atacando a ilha Caju para tomar conta do depósito de carvão da Estrada de Ferro Central. Isso teria causado uma "grande mortandade” e que havia "pânico geral [na] cidade; todos receosos [da] possibilidade [de] saque pela canalha com armamento aperfeiçoado que deu [o] Marechal [a] pretexto [de] batalhões patriotas” (SILVA, 1974, p. 279).

Esses acontecimentos fizeram com que os diplomatas e os comandantes estrangeiros se reunissem no dia 2 de outubro. Desse encontro saiu a deliberação que, por meio de uma nota coletiva dos comandantes, seria feita uma intimação ao Almirante Custódio de Melo no sentido de impedir que ele praticasse qualquer ato hostil contra a cidade, sob pena de a esquadra estrangeira utilizar a força para se opor. Da mesma forma, o governo brasileiro foi notificado sobre a necessidade de retirar as artilharias de cima dos morros, sob pena de ser retirada a intimação feita a Custódio de Melo, o que significaria permitir o bombardeio à Capital Federal. 
Joaquim Nabuco em seu livro A Intervenção Estrangeira na Revolta da Armada, publicado em 1896, enfatizou que esse momento marcou uma alteração no posicionamento dos países estrangeiros com navios na baia de Guanabara. De acordo com ele, até então, a política dos países estrangeiros havia sido de neutralidade e não intervenção nos negócios internos do Brasil. Todos os contatos que haviam sido feitos com ambas as partes eram de caráter oficioso. Contudo, a partir dessa conferência, de 2 de outubro, ficou marcada a intervenção estrangeira na Revolta da Armada. Após trocas de notas e correspondências entre os representantes estrangeiros, os revoltosos e o governo, foi estabelecido aquilo que ficou conhecido como Acordo de 5 de outubro.

Durante três mezes assistir-se-há na bahia do Rio de Janeiro a um verdadeiro duello de artilharia regulado, tiro por tiro, pelas testemunhas reunidas a bordo de um dos navios de guerra estrangeiros. São ellas que dirão, quasi diariamente, a cada um dos combatentes o que lhes é licito e o que lhes é defeso, o que cabe e o que não cabe no accôrdo que fizeram; são ellas que marcarão a raia do tiro; que observarão d'onde partem as provocações; que decidirão, em uma palavra, as questões occurrentes, tudo como os padrinhos em uma pendência de honra (NABUCO, 1896. p. 27).

De acordo com Joaquim Nabuco, o Acordo de 5 de outubro alterou o equilíbrio de forças durante a revolta. Para ele, com essa intervenção o Governo economizou um exército, supriu a falta de uma esquadra, e ganhou tempo para organizar a defesa da cidade. Já os revoltosos, por sua vez, eram paralisados com essa intervenção, sendo essa inação, em sua opinião, a causa primária do fracasso da revolta.

A visão contrária à tese de Joaquim Nabuco foi publica por Felisbelo Freire no livro História da Revolta de 6 de Setembro de 1893, publicado posteriormente ao livro de Nabuco no mesmo ano de 1896. Para esse membro do governo Floriano, a intervenção estrangeira na revolta deixava transparecer a predileção dos representantes e comandantes estrangeiros em relação aos revoltosos em vez do governo legalmente constituído. Para Freire (1982, p. 175) ficou claro que o Acordo de 5 de outubro “(...) no mesmo dia em que foi ele celebrado, foi violado no ataque à Gamboa e tentativa de apreensão do vapor Barão de S. Diogo”. Dessa forma, as potências nunca chegaram a cumprir de fato o Acordo, pois achavam difícil determinar de onde partiam as provocações, se das baterias de terra ou das lanchas rápidas dos revoltosos.

Nesse contexto do Acordo de 5 de outubro, o Conde de Paço D’Arcos continuou a externar em seus relatórios sua preocupação com a ordem. No dia 6 de outubro, ele informou a Lisboa que "quasi todos os dias há combates entre a esquadra revoltada e as fortalezas e as 
ballas ou granadas perdidas vêem cahir na cidade e fazem estragos e causam mortes”. Nada parecia ter mudado, uma vez que “o pânico é geral!”. Da mesma forma que se temia um bombardeio, "não é menor o temor d'um saque por parte da canalha armada que a pretexto de batalhões de voluntários e guarda nacional faz a guarnição da cidade”. De acordo com esse diplomata, "todos receiam portanto que n’um acto de desespero, ao ver-se perdido se a revolução for vencedora, o governo do Marechal possa dar de rédeas a essa canalha que praticará horrores” (SILVA, 1974, p. 281).

No final de outubro, no relatório do dia 24, o Conde de Paço D’Arcos fez algumas reflexões sobre a Revolta da Armada que demonstram todo o seu conservadorismo e defesa da ordem social. Para ele, mais do que uma revolução, essa revolta era "uma lucta de classe entre a marinha que está com o Almirante, e a força de terra que está com o Marechal” (SILVA, 1974, p. 296). O documento prossegue com uma caracterização dos grupos sociais que defendem o governo e o Almirante revoltoso. Nessa parte do documento, é interessante ver a forma distinta com que esse diplomata descreveu quem apoiava os revoltosos e quem defendia o governo, já que “o povo da cidade não se mette na luta” (SILVA, 1974, p. 297) ${ }^{7}$.

Ao lado dos revoltosos estariam "homens e mulheres de todas as posições, mas principalmente das classes mais elevadas”, uns se expressando abertamente a favor do Almirante, outros pela necessidade de “uma mudança radical”. Enquanto que do lado do governo, estão "os radicais avançados dos grupos dos três ministros - Fernando Lobo, Felisberto Freire e Felipe Pereira - é a canalha das ruas que forma os batalhões - Tiradentes, 23 de Novembro e Leaes Acadêmicos (com mais barbeiros e vadios do que estudantes)”. A descrição desse grupo de apoio a Floriano Peixoto prossegue com "a guarda nacional, em que com os capoeiras alistados e bem pagos, servem (obrigados à força de maus tratos) alguns homens de bem!" (SILVA, 1974, p. 297).

Fica explícito nesse documento que, para o Conde de Paço D’Arcos, o grupo que defende o governo, paradoxalmente, é aquele que difunde a desordem social. Dessa forma, não é de se estranhar que alguns autores tenham interpretado que esse diplomata tivesse certa simpatia pelos revoltosos. Parece-nos que o argumento da simpatia não é o suficiente para caracterizar a leitura política desse diplomata. As tratativas diplomáticas para impedir o bombardeamento e o constante receio de saques pela "canalha armada" demonstram sua preocupação em defender a ordem social. Para nós, portanto, identificar a sua preocupação em

\footnotetext{
${ }^{7}$ Para José Murilo de Carvalho (2009) o povo foi excluído dos canais formais de participação política após a Proclamação da República em função das exigências eleitorais. Dessa forma, as manifestações populares espontâneas foram os meios encontrados por essa população de participar da política, desmistificando, portanto, a visão de que a população era "bestializada”.
} 
defender a ordem é a maneira mais adequada de dimensionar os seus posicionamentos frente à revolta.

\section{Os “bailes" da discórdia diplomática}

Outro erro grave foram os bailes. Demos este nome, não só aos tiroteios nocturnos com as forças do littoral, como às expedições à Armação, para retirar munições. Muita valentia, muito pouco amor à vida, mas pouco ou nenhum resultado para o bom êxito da revolução ([s.n.], 1895, p. 37).

O Conde de Paço D’Arcos recebeu um telegrama na noite do dia 17 de novembro, do Ministro dos Negócios Estrangeiros, Hintze Ribeiro, nos seguintes termos: "Por motivo que explicar aqui convem que V. venha Lisboa sem demora. Faça communicação Governo brasileiro ficar 1. ' Secretário Encarregado de Negócios. (a) Hintze Ribeiro” (SILVA, 1974, p. 337). No dia seguinte, ele comunicou o governo brasileiro que havia sido chamado em Lisboa e que ficaria Encarregado de Negócios, o Primeiro Secretário da Legação, Manoel Garcia da Rosa. Dessa forma, ele permaneceu como representante diplomático até o dia 20 de novembro de 1893. Nessa data ele entregou oficialmente a Legação ao Secretário (SILVA, 1974. p. 339).

Os motivos que levaram o governo português chamar o seu diplomata de volta a Lisboa nunca foram explicitados para o Conde de Paço D’Arcos. Ele passou o resto de sua vida sem saber por que havia sido destituído do seu posto de diplomata. O seu filho, o Comandante Henrique Corrêa da Silva, ficou responsável de publicar a documentação concernente ao período em que o seu pai esteve à frente da Legação portuguesa no Rio de Janeiro. Contudo, nem o pai nem o filho ficaram sabendo a razão que motivou a remoção do diplomata.

Os netos do Conde de Paço D’Arcos ficaram responsáveis por terminar a compilação para publicar o livro. Entretanto, permanecia sem explicações o motivo da remoção desse diplomata. Após uma intensa pesquisa nos arquivos diplomáticos de Portugal, sem nunca encontrar nada, eles solicitaram ao representante diplomático brasileiro em Lisboa que fosse buscado nos arquivos brasileiros alguma informação para desvendar o motivo da remoção. Foi a partir dessa investigação que foi encontrado o documento, datado de 18 de novembro de 1893, endereçado ao Ministro das Relações exteriores do Brasil, Alexandre Cassiano do Nascimento, e assinado pelo representante brasileiro em Portugal, Vianna de Lima (SILVA, 1974. p. XIII-XIV). 
Nesse documento ficou explícita a solicitação do governo brasileiro ao governo de Portugal que removesse esse diplomata, porque ele estava se envolvendo abertamente na política brasileira. A reação de Hintze Ribeiro, que além de Ministro dos Negócios Estrangeiros era o Presidente do Conselho Ministerial de Portugal, foi acatar o pedido.

Desde a publicação desse livro em 1974, essa versão foi repetida tanto pela historiografia brasileira quanto pela portuguesa ${ }^{8}$. Para nós, a remoção desse diplomata reside mais nos elementos explicativos da sua visão de mundo, do que na sua participação política efetiva. O Conde de Paço D’Arcos foi um militar da Marinha portuguesa e defendeu a necessidade de respeito à hierarquia militar.

A sua atuação durante a conflagração da revolta foi a causa primordial que desencadeou a solicitação brasileira. Para ele, a diplomacia deveria ser respeitada da mesma forma que a hierarquia militar. Portanto, no transcorrer do conflito ele permaneceu irredutível em suas exigências de reparações diplomáticas aos episódios de desacato à bandeira portuguesa, ou em casos de desrespeito às formalidades diplomáticas.

Evidentemente, o governo brasileiro não poderia requerer a remoção de um diplomata sem um bom motivo. Dessa forma, o argumento utilizado foi de que o representante português estava se envolvendo diretamente na política brasileira ${ }^{9}$. Contudo, o que a documentação existente no Arquivo Histórico do Itamaraty deixa transparecer, é que o Conde de Paço D’Arcos não compreendeu a gravidade da situação em que o governo brasileiro se encontrava. Conseqüentemente, por ficar reivindicando pedidos de satisfações diplomáticas por escrito, ele passou a ser tornar inconveniente para o governo brasileiro que tinha que responder às suas solicitações - embora o Conde de Paço D’Arcos estivesse no pleno exercício de seus direitos e funções.

\footnotetext{
${ }^{8}$ Os livros Janotti (1986), Queiroz (1986), e Penna (1997) utilizaram a documentação do Conde de Paço D’Arcos para referendar a argumentação das suas respectivas teses. Contudo, nenhum deles analisou a fonte, apenas citaram esparsos documentos presentes na publicação de 1974. Na mesma situação se encontra o artigo de Heinsfeld (2007). O único trabalho que analisou a documentação foi a dissertação do autor português Eduardo Cândido Cordeiro Gonçalves (1995). O autor citou as dificuldades diplomáticas que geraram o pedido de afastamento do Conde de Paço D’Arcos, contudo, de forma limitada, ele apenas reproduziu a visão da publicação de 1974. Outros dois autores brasileiros também trabalharam com essa documentação recentemente. O primeiro foi Amado Cervo (2000), que embora tenha acessado documentos de Portugal, igualmente, se limitou a reproduzir a mesma explicação existente na publicação de 1974. O segundo autor brasileiro foi Sérgio Corrêa da Costa (2001), que se contentou em reproduzir diversos trechos documentais sem fazer nenhuma reflexão sobre os mesmos. Embora o autor tenha citado a formação militar e política conservadora do Conde de Paço D’Arcos, em nenhum momento elaborou alguma explicação que articulasse que a visão política desse diplomata pudesse ser condicionada por esses elementos.

${ }^{9}$ Acrescenta-se o fato que no mês de Agosto de 1893 jornais de Portugal publicaram trechos de documentos do Conde de Paço D’Arcos em que esse comunicava à Lisboa suas impressões políticas sobre a República. Os jornais do Brasil reproduziram-nos causando péssima impressão e deixando o diplomata em uma situação constrangedora. Sobre esse episódio ele comentou que "lamento o facto, que produziu aqui o peor e o mais desagradavel efeito" (SILVA, 1974, p. 249-252).
} 
Esses pedidos iniciaram, mais precisamente, no dia 30 de agosto de 1893. Ou seja, nas vésperas da Revolta da Armada já é possível identificar as diretrizes que esse representante conferiu para diplomacia portuguesa.

O Conde de Paço D’Arcos, no dia 30 de agosto, enviou um documento para o Comandante Augusto de Castilho, da corveta Mindelo. Nesse documento, ele relatou que o diplomata inglês havia lhe comunicado que as autoridades da Marinha brasileira não estavam cumprindo "todas as formalidades do cerimonial marítimo" com o Comandante naval da Inglaterra. A situação havia chegado "ao ponto de não lhe serem pagas pessoalmente algumas visitas feitas com caráter oficial pelo referido comandante Lang; e que, embora esse comandante se não queixasse oficialmente, havia estranhado as faltas do devido cerimonial” (SILVA, 1974, p. 254). Dessa forma, o diplomata português solicitou ao Comandante Castilho que lhe informasse caso enfrentasse situações semelhantes.

No primeiro mês da Revolta da Armada, as negociações diplomáticas entre representantes estrangeiros, revoltosos e governo, assim como os relatórios enviados para Lisboa, ganharam as atenções desse diplomata. Somente em 10 de outubro que ocorreu um incidente entre marinheiros brasileiros e portugueses, no Cais dos Mineiros no Arsenal da Marinha, que exigiu uma satisfação diplomática ${ }^{10}$. O Conde de Paço D’Arcos enviou uma nota ao Ministro das Relações Exteriores do Brasil, Carlos de Carvalho, solicitando providências para que não se repetissem as “desagradáveis occorrencias”. Para ele, os soldados e marinheiros eram "quasi sempre homens sem educação e sem conhecimento de conveniências políticas, podem a continuar as cousas como hontem se deram lançar-se em qualquer serio conflito, que venha criar graves embaraços” (SILVA, 1974, p. 283) Assim, Carlos Eugênio esperava que o governo brasileiro expedisse ordens para que a tropa fixada no Cais dos Mineiros não provocasse os marinheiros que ali se apresentassem.

O Ministério das Relações Exteriores respondeu, no dia 14 de outubro, ao Ministro Plenipotenciário de Portugal que o caso seria enviado para o Ministério da Guerra, "para que se tome na devida consideração” (AHI-RJ, 288/04/08, 14.10.1893). No dia 21 de outubro, o Ministro Carlos de Carvalho comunicou o desfecho do caso. O documento revela que "das indagações a que o Ministério da Guerra mandou proceder resulta ser um sargento o

\footnotetext{
${ }^{10} \mathrm{O}$ patrão do bote português, Felipe Dias do Amaral, relatou que no dia 10 de outubro, às $17 \mathrm{~h}$, depois de ter começado o bombardeamento, o referido bote foi insultado com palavras e gestos obscenos por alguns soldados e outras praças graduadas que estavam no recinto do Arsenal da Marinha fronteiro ao cais. Os insultos, de acordo com o relato, não foram provocados ou respondidos pela marinhagem portuguesa. O patrão do bote, Felipe Dias do Amaral, desembarcou e foi reclamar para o capitão do exército, que efetivamente, repreendeu os soldados. Contudo, depois que o capitão se retirou, os insultos reiniciaram. Ver: Arquivo Histórico do Itamaraty - RJ Estante 288/ Prateleira 02/ Maço $12-10.10 .1893$
} 
responsável pelos atos que deram causa a referida queixa”. Esse sargento declarou que não tinha “intenção de offender os brios daquelles marinheiros nem o paiz da sua nacionalidade”. Porém, esse sargento foi "repreendido severamente pelo Capitão do destacamento, o foi também mais tarde pelo Major fiscal” (AHI-RJ, 288/04/08, 21.10.1893). O Ministro concluiu o documento declarando estar certo de que não se reproduziriam fatos semelhantes daquele momento em diante.

Após a solução desse episódio e a promessa do governo no sentido de não se repetir os desagradáveis acontecimentos, esse diplomata se dedicou inteiramente à questão da intervenção estrangeira na Revolta da Armada. Porém, no dia 2 de novembro, aconteceu uma significativa ocorrência que exigiu que o Conde de Paço D’Arcos enviasse uma nota enérgica ao governo brasileiro. Esse documento (nota 1) declarava que com "muito sentimento" ele participava ao governo brasileiro "que um grave attentado foi commetido por forças do governo legal contra o respeito devido à bandeira portuguesa”. O documento prossegue narrando que,

(...) sobre uma embarcação do serviço da Corveta Mindello, com bandeira e flâmula arvoradas, com um official a bordo e ainda com claridade bastante para que tudo bem podesse ser visto, forças armadas dos postos do littoral atiraram duas descargas sobre a referida embarcação.

Este facto, embora praticado por subalternos, é de tal maneira attentatorio à dignidade de Portugal, que o abaixo assignado não pode deixar de pedir para elle reparação própria à desafronta da nação que representa e confiadamente espera na lealdade do Governo Brazileiro que ella lhe seja dada (AHI-RJ, 288/02/12, 02.11.1893 grifos nosso) ${ }^{11}$.

Essa nota foi recebida pelo Ministro das Relações Exteriores, Cassiano do Nascimento, que respondeu ao diplomata português no dia 4 (resposta 1). Nessa resposta, foi informado de que o Ministério da Guerra seria acionado para prestar os "necessários esclarecimentos” (AHI-RJ, 288/04/08, 04.11.1893). Contudo, no dia 7 de novembro o Conde de Paço D’Arcos ainda não havia recebido nenhuma satisfação diplomática sobre o episódio. Dessa forma, ele enviou nova circular (nota 2) ao governo brasileiro lembrando que na ocasião da entrega da primeira reclamação (nota 1), o próprio Ministro Cassiano do Nascimento lhe assegurou verbalmente que "a mais completa reparação seria dada com brevidade; porque o Governo Brazileiro não permittia que os seus subalternos, ainda mesmo por ignorancia, praticassem actos de desacato para com uma nação amiga”. Para esse diplomata,

\footnotetext{
${ }^{11}$ Disponível também em: SILVA, 1974. op. cit. p. 316. [despacho de 02.11.1893]
} 
Não parece ao abaixo assignado, que em assunto de tal gravidade seja justificável esta demora na reparação própria e menos ainda que em vista da sua nota acompanhada e comprovada com a representação do Commandante e participação do respectivo official, sejam ainda necessárias outras informações, que só podem servir para dilatar o acto da reparação que é devida à Nação que representa, ou diminuir o alcance político da mesma reparação.

O abaixo assignado confia na lealdade do Governo Brazileiro, que se apressará a resolver este assumpto na forma devida (...) (AHI-RJ, 288/02/12, 07.11.1893 grifos nosso) ${ }^{12}$.

A situação se agravou porque no dia 8 de novembro o Conde de Paço D’Arcos enviou nova nota de protesto sobre um incidente ocorrido no dia 6 de novembro de 1893 (nota 3). Esse documento apontou para outros dois acontecimentos. O primeiro foi que o Comandante Castilho recebeu a notícia que "uma lancha arvorando illegalmente a bandeira portugueza, passara da Gamboa para a bahia de Bota-Fogo conduzindo - ao que lhe afirmavam munições de guerra para as fortalezas do governo". A reação desse Comandante foi enviar uma lancha a vapor e um escaler, armados em guerra, para prender a dita lancha, no "uso incontestável do pleno direto de fiscalização à sua bandeira nacional”. Contudo, a lancha não foi aprisionada. Dessa forma, ao retornar para perto da corveta Mindelo, ocorreu o segundo fato: "No regresso para bordo, às 5 horas da tarde, foram as embarcações da Corveta atacadas por seguido fogo de fusilaria que lhe foi feito da praia, ou caes da Glória, pelas forças militares do governo da República”.

O documento seguiu fazendo uma enérgica cobrança ao governo brasileiro, nos seguintes termos:

\footnotetext{
Abstraindo mesmo do caso - que aliás não está provado - de uma lancha do serviço do Governo arvorar indevidamente a bandeira portugueza, resta o facto inaudito e inqualificavel de um posto militar do Governo legal ter feito fogo sobre embarcações de guerra portuguezas, com perfeito conhecimento da offensa que se praticava à luz do dia sobre a bandeira de uma Nação amiga e allianda, completamente neutral na lucta intestina do Brazil, lucta que não justifica nem desculpa este attentado ao direito internacional.

O abaixo assignado, forte com o seu direito de representante de Portugal protesta em nome do seu Governo contra o facto citado do qual pede reparação condigna e breve com lhe é devida.

Aproveitando esta occasião faz lembrar que ainda espera resposta e reparação de um igual caso (...) (AHI-RJ, 288/02/12, 08.11.1893) ${ }^{13}$.
}

\footnotetext{
12 Disponível também em: (SILVA, 1974. p. 317).

${ }^{13}$ Disponível também em: (SILVA, 1974. p. 318-319).
} 
O Conde de Paço D’Arcos enviou outras duas notas de caráter urgente no mesmo dia 8 de novembro. A primeira foi para o Comandante Castilho, informando que havia enviado para o governo brasileiro a reclamação sobre os recentes acontecimentos que envolviam a embarcação portuguesa (nota 3). Também declarou para esse comandante que só não levou pessoalmente o protesto ao Itamaraty porque estava incomodado de saúde, mas garantiu que "não abandono porem a questão, que ainda espero será resolvida de forma que não nos seja desagradável” (SILVA, 1974, p. 318). O segundo telegrama foi para o governo de Portugal, comentando que as forças armadas do governo brasileiro haviam atirado duas vezes descargas de fuzilaria contra os escaleres da Corveta Mindelo. E que “já está feita reclamação muito energica” (SILVA, 1974, p. 319).

A situação, que já estava delicada em função das notas de protesto (1, 2 e 3) expedidas pelo Ministro Plenipotenciário de Portugal, deteriorou-se quando esse diplomata enviou um relatório para o Itamaraty, no dia 9 de novembro, descrevendo uma nova ocorrência (nota 4). De acordo com o Conde de Paço D’Arcos, no dia 7 de novembro, houve uma discussão entre o Comandante Augusto de Castilho e o Vice-Almirante Coelho Netto.

A contenda girava em torno do lugar correto para as embarcações estrangeiras atracarem no Arsenal da Marinha. O primeiro defendia que uma ponte de madeira fazia parte do Arsenal, podendo, portanto, atracar nesse ponto. O segundo dizia que foi determinado que os barcos estrangeiros só atracassem num cais de pedra - que ficava fora da esplanada do Arsenal. Dessa forma, estabeleceu-se uma discussão entre ambos. O Conde de Paço D’Arcos relatou que o Vice-Almirante disse de uma maneira severa que "se o Comandante desobedecesse ficava subjeito às consequências!”. O documento prossegue da seguinte forma:

A tão injustificável agressão que lher era feita por pessoa de tão elevado grau social, por militar da mais elevada patente! Que assim faltava num momento de nervoso despeito às mais elementares attenções para com um official superior, um Commandante estrangeiro! Este só replicou com toda a calma e cordura e ainda com o respeito militar e social convenientes à alta hierarquia do Exmo. Snr. Coelho Netto "que estava preparado para todas as consquencias, mas que lhe declarava que se ia queixar da gratuita affronta que lhe era feita".

Eis o caso relatado na sua maior singeleza.

Snr. Ministro, expondo este desagradável conflicto, não pode o abaixo assignado deixar de chamar para o mesmo a mais seria attenção de V. Ex. ${ }^{a}$. Sem razão alguma, imprudentemente e fora de todas as formulas normaes da mais simples delicadeza official e militar, um oficial da marinha portugueza commandante das forças navaes da sua nação no Rio de Janeiro, foi, dentro de um estabelecimento do Estado bruscamente tratado por um general da Armada brazileira da mais elevada patente e em acto de serviço. Não se trata duma offensa particular de que se tome desforço pessoal segundo as praxes 
sociais, trata-se duma affronta feita sem causa que a justifique a um official estrangeiro com vexame a menos preço da Nação que representa.

Chamando para o caso a atenção do Governo, o abaixo assignado espera que condignamente seja reparada a affronta gratuitamente feita a um official da sua Nação (SILVA, 1974, p. 322).

Evidentemente, essa avalanche de notas de protestos não teve uma boa repercussão no Ministério das Relações Exteriores do Brasil. Tal análise se confirma quando se verifica que no dia em que foi elaborada a resposta (resposta 2) à primeira ocorrência (notas 1 e 2), foi enviado um telegrama confidencial ao diplomata brasileiro em Lisboa, Vianna de Lima, com instruções para solicitar ao governo de Portugal a remoção de Carlos Eugênio Corrêa da Silva do Brasil, pois esse estaria se envolvendo abertamente na política (SILVA, 1974. p. XIIIXIV).

A resposta aconteceu no dia 10 de novembro de 1893 (resposta 2). Por considerar esse documento essencial para compreender os motivos que causaram a remoção do Conde de Paço D’Arcos de suas funções no Brasil, resolveu-se transcrever a maior parte no corpo do texto.

Não posso occultar ao Snr. Ministro a estranheza que causou-me a celeridade que reclama na solução deste assumpto, nas circunstâncias atuais. Ao Ministério a meu cargo cumpria, como o fez, pedir esclarecimento às autoridades competentes. Se para o senhor Ministro a representação do Comandante da corveta Mindello e a parte de um dos seus oficiais sobre o ocorrido são provas suficientes, não eram dispensáveis para o governo do Brasil as informações das suas autoridades que lhe merecem plena confiança. Dahi a demora, que considero justificável.

Passo agora a expor ao senhor ministro o que consta das partes oficiais.

O Comandante que estava a serviço no litoral da Gamboa no dia 1 do corrente, fez fogo sobre a lancha que se trata, por julga-la pertencer aos revoltosos, não só pela distancia em que a mesma se achava, já porque, sendo bastante escuro, não pode divulgar todas as cores da bandeira portuguesa, parecendo-lhe pela cor branca, ser o distintivo da esquadra revoltosa. Além disso a lancha muito se assemelha a de um nome "Gloria" em poder da mesma esquadra, e é pintada com esta das cores branca e preta. Acresce que a referida lancha da corveta Midello não atendeu à intimação que lhe foi feita, pelo que o Comandante já mencionado, receiando uma agressão, mandou fazer fogo duas vezes para o ar, como meio mais seguro de afasta-la da terra.

* Mas não houve ofensa à bandeira portuguesa, e, para prova-lo, cabe-me ponderar ao senhor Ministro que o dito Comandante só teve conhecimento que a lancha era portuguesa, depois da comunicação deste Ministério.

Tenho a honra(...) Cassiano do Nascimento.

* Peço permissão para retificar a parte da nota do senhor Conde que se refere a reparação por mim prometida. Em conferência assegurei que o governo do Brasil a faria completa no caso de [julgar] convencido que se dera um desacato (AHI-RJ, 288/04/08, 10.11.1893). 
A relação entre o Conde de Paço D’Arcos e o Ministério das Relações Exteriores do Brasil estava, portanto, tensa. O diplomata, sempre fiel aos preceitos de defesa da ordem e hierarquia, reclamou com veemência por notas de protesto (notas 1, 2, 3 e 4). Ele estava no seu direito incontestável de exigir reparações diplomáticas aos episódios que desonraram a Marinha portuguesa. Porém, ele não soube dimensionar corretamente a gravidade do momento enfrentado pelo governo brasileiro. O perigo eminente de um bombardeio ou invasão pelos revoltosos consumiam as energias governamentais no sentido de evitar essas contingências. Dessa forma, as suas notas de protesto não foram bem recebidas no transcorrer de uma situação delicada. Contudo, o diplomata português permaneceu irredutível em suas exigências de reparações.

Depois de receber essa nota do governo brasileiro (resposta 2), o Conde de Paço D’Arcos persistiu em seu intento. No dia 11, ele comunicou ao Comandante Augusto de Castilho a resolução que o governo havia conferido ao primeiro caso (nota 1 e 2). O seu comentário é de que "não occulto a V. Ex. ${ }^{a}$ que esta resposta não me satisfaz. Sem negar o facto em absoluto, desculpa-se com a escuridão e com terem sido as descargas da fusilaria feitas para o ar!”. A sua ideia era esperar as respostas do governo sobre os outros dois conflitos (notas 3 e 4) para depois se pronunciar novamente. O representante português estava tão resoluto em enfrentar essa crise diplomática que confessava a Castilhos que "veremos se, como é de se esperar, o nosso Governo entende dar-me algumas instrucções; mas quer as tenha, quer não, eu não abandono esta questão, que considero de dignidade nacional” (SILVA, 1974, p. 323 grifos nosso).

As instruções do governo de Portugal vieram por telegrama às $16 \mathrm{~h}$ de 16 de novembro de 1893. Diziam que “convem na anormal situação desse paiz defender interesses nossos súbditos evitando quanto possível incidentes difficeis liquidar-se. (a) Hintze Ribeiro” (SILVA, 1974, p. 328).

Para Amado Cervo (2000, p. 218), essa ordem expedida pelo governo português deixava dúvidas sobre a atitude a ser tomada frente às dificuldades. A opinião de Eduardo Gonçalves (1995, p. 148) é de que esse telegrama era um “aviso” aos protestos enérgicos que o Conde de Paço D’Arcos vinha fazendo ao governo brasileiro. No ponto de vista de Sérgio Corrêa da Costa (2001, p. 240), o telegrama de Hintze Hibeiro pegou o diplomata “desprevenido”.

Sob esse ponto de vista, as instruções do governo português são claras. O Brasil atravessava um momento político atípico. Dessa forma, não era o momento de criar incidentes 
diplomáticos que fossem difíceis de solucionar ${ }^{14}$. O principal objetivo, naquele momento, era garantir os interesses dos súditos portugueses que residiam naquela Capital Federal. Contudo, para um indivíduo defensor da ordem e da hierarquia militar, as reparações diplomáticas eram primordiais e não poderiam ser relevadas ou esquecidas.

Convém lembrar outro ponto importante. Esse telegrama foi expedido no transcorrer do dia 16 de novembro e chegou às mãos do Conde de Paço D’Arcos por volta das $16 \mathrm{~h}$ (telegrama 1). De acordo com o documento de Vianna Lima, o Ministro dos Negócios Estrangeiros de Portugal passou em sua casa por volta das 18h do dia 16 de novembro, e, somente então, Hintze Ribeiro ficou ciente de que o seu diplomata no Rio de Janeiro estava “se envolvendo na política nacional”. Ainda segundo o mesmo documento, só no dia 17 que Hintze Ribeiro enviou ordens (telegrama 2) para o retorno de Carlos Eugênio Corrêa da Silva para Portugal.

Assim, é necessário contextualizar o telegrama em que Hintze Ribeiro instruiu o seu diplomata sobre qual procedimento adotar perante as queixas diplomáticas (telegrama 1). Ou seja, quando foi expedido esse telegrama, o Ministro não imaginou que duas horas mais tarde seria solicitada a remoção daquele diplomata do Rio de Janeiro. Portanto, pode-se inferir que as instruções eram no sentido de pacificar as relações entre diplomata e governo.

Essa contextualização reforça o argumento de que o Conde de Paço D’Arcos não soube dimensionar corretamente a situação política brasileira. O Ministro dos Negócios Estrangeiros, um experiente político, considerou que naquele momento o ideal era não criar incidentes difíceis de solucionar. Dessa forma, parece que as defesas da ordem e da hierarquia militar, que sempre pautaram a leitura política desse diplomata, acabaram por atrapalhar o seu discernimento político.

O documento que foi enviado para Portugal no dia 17 de novembro - o Conde de Paço D’Arcos recebeu o telegrama (telegrama 2) no dia 17, à noite, - demonstra que até o último

\footnotetext{
${ }^{14}$ O filho do Conde de Paço D’Arcos, o Comandante Henrique Corrêa da Silva, autor do prefácio do livro que contém a documentação analisada nesse trabalho, salientou um episódio ocorrido no dia 8 de setembro, que foi assim informando para Lisboa pelo seu pai: "Hontem força armada de terra fez fogo sobre escaler guerra italiano transportar seu cônsul, matar um marinheiro. Vice-Presidente da Republica deu satisfação faz enterro pomposo". (SILVA, 1974, p. 264) Para o Comandante Henrique, "o governo brasileiro tendo adotado com a grande nação italiana procedimento diametralmente oposto àquele que, de colaboração com o Ministério dos Estrangeiros de Lisboa, adoptou com a pequena mas não menos nobre pátria portuguesa, não ganhou louro algum para o seu brasão" (SILVA, 1974, p. LVII). Contudo, note-se que todos os casos de pedidos de reparação diplomática enviados pelo Conde de Paço D’Arcos foram baseados em: insultos, ofensas, dignidade, desafronta, (des) respeito, (in) delicadeza, etc. Todos esses argumentos são válidos para se exigir reparação diplomática. Entretanto, desde o dia 11 de setembro passou a vigorar Estado de Sítio, que suspendeu todas as garantias constitucionais, salientando a gravidade da situação política interna. Isso explica em parte a pronta reparação diplomática no caso italiano, ocorrido no dia 8 de setembro, e a lentidão nos casos envolvendo Portugal.
} 
momento, ele permaneceu irredutível. Esse diplomata discordava da opinião do seu superior que pensava que a situação política brasileira era anormal (telegrama 1). Para Carlos Eugênio,

Os casos que agora se deram não podem ser considerados simplesmente como acontecimentos fortuitos deste estado anormal de cousas. São antes revelações manifestas da má vontade de certas classes da população brasileira contra os portugueses, quer por força do espírito de nativismo (como aqui se diz) quer por inveja a homens que prosperam pelo seu incessante labor tão contrário à índole e gênio deste povo, quer mesmo por ódio aos antigos dominadores; e tudo isso exacerbado nestas ultimas épocas pela propaganda de rivalidades e de raiva levantada pela imprensa demagogica - em que infelizmente predomina o elemente renegado, para nós o mais perigoso e prejudicial - vociferando contra tudo e todos do Portugal monarchico (SILVA, 1974, p. 328-329).

No dia 20 de novembro de 1893 o Conde de Paço D’Arcos entregou a Legação para Manuel Garcia da Rosa, finalizando a sua participação e testemunho no conflito.

\section{Conclusões}

O Conde de Paço D’Arcos foi o primeiro diplomata português a representar Portugal no Brasil republicano. Consigo trouxe uma maneira específica de compreender o mundo. A sua formação militar dentro da Armada portuguesa, onde ocupou diversos cargos políticoadministrativos, assim como sua vinculação política ao Partido Regenerador de Portugal, assumindo mandatos junto a Câmara dos Deputados e a Câmara dos Pares, inclusive como Governador Civil de Lisboa, influenciaram de maneira decisiva sua percepção política.

Portanto, ao testemunhar diversos episódios sobre a política brasileira, sobretudo na Revolta da Armada de 6 de setembro de 1893, suas impressões foram pautadas pela defesa da ordem social e da hierarquia militar. De certa forma, essa sua visão de mundo acabou prejudicando as relações entre ele o governo brasileiro que interpretou as suas constantes defesas da ordem e da hierarquia nas relações diplomáticas, como uma participação na realidade política brasileira - intervenção nos assuntos internos do país. Isso gerou o pedido de remoção desse diplomata de suas funções no Brasil. 


\title{
A DIPLOMAT IN THE "REVOLTA DA ARMADA" (Brazilian Naval Revolt): political impressions and the role of Count of Paço D'Arcos.
}

\begin{abstract}
The first diplomat that represented Portugal in the Brazilian Republic was Carlos Eugênio Corrêa da Silva, the Count of Paço D’Arcos. His Diplomatic Mission took place from 2 June 1891 to 20 November 1893. In his reports about the Brazilian political situation, arguments on social order defense and military hierarchy are recurrent, especially during the Armed Forces Insurrection. This article proposes to study diplomatic forces in order to understand the impressions and actions of this diplomat during this conflict.
\end{abstract}

Keywords: Count of Paço D’Arcos, diplomacy, Brazil and Portugal, politics, regional insurrections.

\section{Referências}

[s.n.]. Notas de um revoltoso: diários de bordo. Rio de Janeiro: Typ. Moraes, 1895. Arquivo Histórico do Itamaraty - RJ

BONIFÁCIO, Maria de Fátima. "A guerra de todos contra todos: ensaio sobre a instabilidade política antes da Regeneração”. In: Análise Social. Vol. XXVII (115), 1992 (I. º), p. 91-134.

CARONE, Edgard. A República Velha: A Evolução Política (1889-1930). 4ed. São Paulo: DIFEL, 1983. 2v.

CARVALHO, José Murilo de. Os Bestializados: O Rio de Janeiro e a República que não foi. 3ed. São Paulo: Cia das Letras, 2009.

CERVO, Amado; MAGALHÃES, José Calvet de. Depois das Caravelas: As relações entre Portugal e Brasil 1808-2000. Brasília: Editora da Universidade de Brasília, 2000.

COSTA, Sérgio Corrêa da. Brasil, segredo de Estado: Incursão descontraída pela história do país. 2ed. Rio de Janeiro: Record, 2001.

. A diplomacia do Marechal: intervenção estrangeira na Revolta da Armada. Rio de Janeiro: Zelio Valverde, 1945.

FREIRE, Felisbelo. História da Revolta de 6 de Setembro de 1893. Brasília: Editora da Universidade de Brasília, 1982. [primeira edição de 1896].

GONÇALVES, Eduardo Cândido Cordeiro. Ressonâncias em Portugal da Implantação da República no Brasil (1889-1895). Porto: Reitoria da Universidade do Porto, 1995. 
HEINSFELD, Adelar. A ruptura diplomática Brasil-Portugal: um aspecto do americanismo do início da República brasileira. In: XXIV Simpósio Nacional de História. Anais complementares ... São Leopoldo/RS, jul. 2007.

HOMEM, Amadeu Carvalho. “Jacobinos, Liberais e Democratas na edificação do Portugal contemporâneo”. In: TENGARRINHA, José (org.). História de Portugal. 2ed revista e ampliada. Bauru, SP: EDUSC; São Paulo, SP: UNESP; Portugal, PO: Instituto Camões, 2000, p. 341-359.

JANOTTI, Maria de Lourdes Mônaco Os Subversivos da República. São Paulo: Brasiliense, 1986.

MARTINS, Hélio Leôncio. A Revolta da Armada. Rio de Janeiro: Biblioteca do Exército Editora, 1997.

NABUCO, Joaquim. A Intervenção Estrangeira durante a Revolta de 1893. Rio de Janeiro: Typ. Leuzinger, 1896.

PENNA, Lincoln de Abreu. O Progresso da Ordem: O florianismo e a construção da República. Rio de Janeiro: Sette Letras, 1997.

QUEIROZ, Suely Robles Reis de. Os Radicais da República. São Paulo: Brasiliense, 1986.

SILVA, Henrique Corrêa da Silva (org.). Missão Diplomática do Conde de Paço D’Arcos no Brasil (1891-1893). Lisboa, 1974.

SOUZA, Adriana Barreto de. “A serviço de Sua Majestade: a tradição militar portuguesa na composição do generalato brasileiro (1837-50)”. In: CASTRO, Celso; IZECKSOHN, Vítor; KRAAY, Hendrik. Nova História Militar Brasileira. Rio de Janeiro: Editora FGV, 2004, p. 159-178. 